\title{
Empirical Research on the Changes in Share of Worker Compensation in Taiwan
}

\author{
Shang-Jyun Song ${ }^{1}$ \\ ${ }^{1}$ School of Economics and Management, Tsinghua University, Beijing, China \\ Correspondence: Shang-Jyun Song, School of Economics and Management, Tsinghua University, Beijing. Postal \\ code: 20347, No.139-90 of the Zheng-He Road, Keelung, Taiwan. Tel: 886-933-022-918. E-mail: \\ itaiwanformosa@gmail.com
}

Received: November 6, 2014

Accepted: November 22, 2014

Online Published: November 25, 2014

doi:10.5539/ijef.v6n12p264

URL: http://dx.doi.org/10.5539/ijef.v6n12p264

\begin{abstract}
Taiwan's economic development primarily relies on international trade. Recent trade data, however, indicate that mainland China has surpassed the United States as Taiwan's largest trading partner. Meanwhile, Taiwan's unemployment rate has increased and the share of income has decreased, which has consequently widened income disparities. Thus, Taiwanese attribute the decline in worker income to trade with mainland China. This paper reveals the change in the share of worker compensation in Taiwan through empirical research.
\end{abstract}

Keywords: worker compensation, technical progress, international trade, globalization

\section{Summary of the Literature}

In a global context, with the increase in international trade and the international acceleration of funding circulation, economic and technological barriers have been overcome, bringing enormous development to the joint use of technology worldwide and making economic globalization an irreversible trend that affects economic and political development in each country. Heckscher-Ohlin's trade theory holds that developing international trade will increase the worker share of compensation. However, Lee and Jayadev (2005) and Guscina (2006) noted that though globalization advances free trade between countries, it reduces the share of labor in developed countries. This can be seen in the case of the bargaining model. The model explains that with globalization, engagement of countries in competition for investment weakens the negotiation capacities of workers, thereby reducing the worker share of compensation.

In general, research into the worker share of compensation is referred to as the percentage of worker compensation to the country's GDP or GNP. This paper takes the worker share of compensation to GDP as the explanatory variable to analyze the changes in Taiwan worker compensation when the economy is developing.

Kaldor's model of steady economic growth indicates that the share of factor distribution remains unchanged when the economy is experiencing long term growth. In reality, however, Harrison (2002) discovered that in the 1980s, both industrialized countries, such as Europe, United States, and Japan, and developing countries, such as India and Latin America, experienced significant decline in the worker share of compensation. In fact, with time, not only did worker distribution become significantly different between regions but it also differed within the same economy.

As an economy develops, resources and essential factors distributed between each industry are subject to migration. Transformation of industrial structure, though, is an important influencing factor with regards to changes in worker compensation (Serres, 2001; Morel, 2005). Based on Marx's Labor Theory of Value, Zhang $\mathrm{Hu}$ et al. (2009) proved that the changes in secondary industries as against fluctuations in the worker share of compensation are significantly influenced when the workforce is weak. Looking at the development model of advanced countries, Taiwan's industrial structure is currently undergoing change. This change is likely to influence and offset the competitiveness of the labor market and subsequently the percentage of each industry's workforce. Therefore, once the employment structure is influenced by the industrial structure, changes to supply and demand then influence the worker share of compensation.

Kaldor holds that the investment rate (investment/GDP) is the decisive factor in the share of factor distribution, while Findlay (1960) indicates that, in reality, investment rate and ratio of factor input are completely equal. 
In research on the introduction of technical progress, Bentolina and Saint-Paul (2003) discovered that the impact of total factor productivity's technical progress as against the worker share of compensation in OECD countries is significant and negatively correlated, addressing it as "enhancing properties of technical progress." The technical progress in this paper takes a year's time as the dummy variable and the control factor. As time passes, technology continues to develop and progress. With the help of the year dummy variable as an explanatory variable, an analysis is conducted to understand the changes in worker share of compensation at different points of technological progression.

Attracting direct investment from foreign companies is another way to stimulate an open economy. Note that changes to worker compensation with regards to FDI have two contrasting effects. First, capital-intensive and technical progress is likely to bring about negative influences. That is, in regions where there is more foreign economic power and the levels of capital and technology are higher, the share of worker income is lower (Bai et al., 2010). Second, due to increments in the labor market, the intensity of competition between enterprises takes the form of positive strength in relation to the worker share of compensation (Decreuse et al., 2008). Taiwan's economic development continues to expand. According to comparative advantage, high volume import of labor-intensive products that require nontechnical intensive capabilities and foreign investment is likely to cause shifts in local production from labor-intensive products to capital-intensive, and thereafter, progress to the development of technology-intensive products (Xue, 2007). As a result, the compensation in labor-intensive industries decreases and the wage disparity of each industry widens. This paper adopts an overall perspective to explain the impact of increased international trade and foreign investment on worker compensation in Taiwan.

Luo Chang Yuan (2008) notes that the deciding factors with regard to the share of essential factors include the ratio between capital and production, standard of technical progress, globalization, and standard of economic development. In addition, this paper refers to studies such as En and Jie (2010) to analyze the econometric model of mainland China's worker share of compensation. In terms of the econometric model analysis with regards to the change in worker share of compensation in Taiwan, utilized variables, including the ratio between capital and production, year dummy variable, import and export dependence, percentage of foreign direct investment to GDP, ratio of the local economy, financial depth, tax level, and industry structure.

\section{Model Construction}

In Figure 1, the percentage of worker compensation in Taiwan with regards to GDP reveals an inverted U-shape curve. Since 1991, the worker share of compensation has continued to decline. In 1999, it broke to its lowest point since 1981, while as compared with 1991, it declined by $7.48 \%$ with no signs of slowing. From 2000 to 2010 , in the 11 years, the worker share of compensation declined by $7.53 \%$.

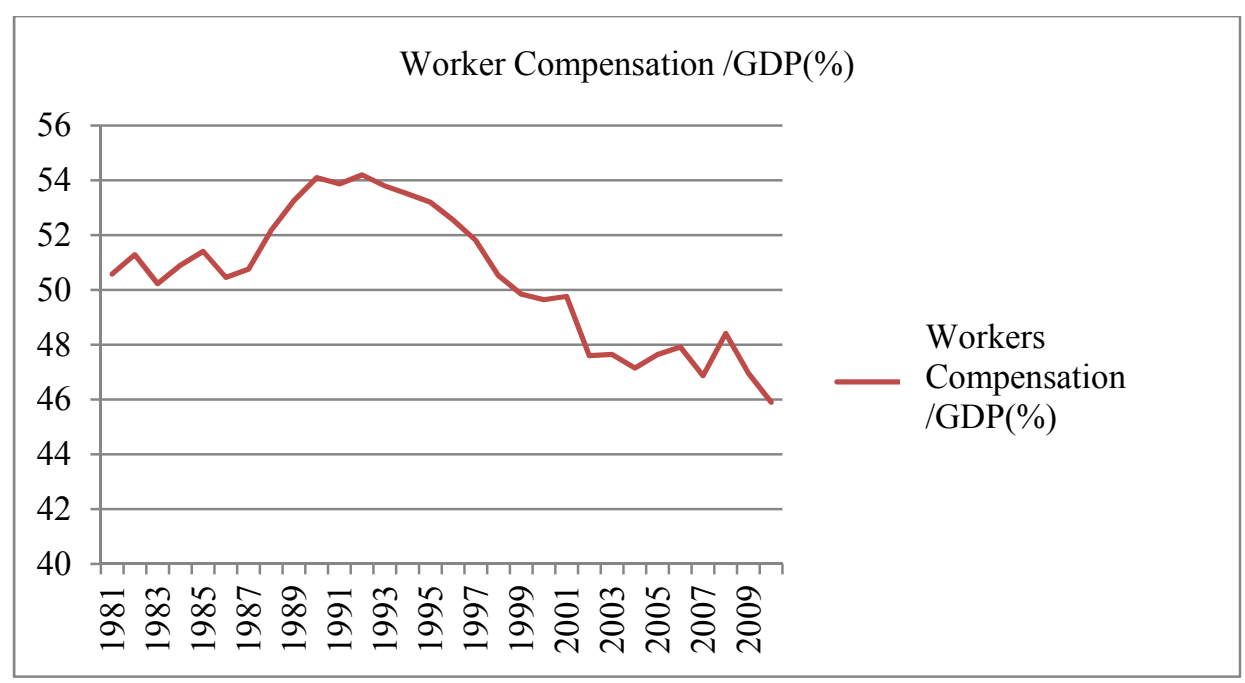

Figure 1. Share of worker compensation to GDP

Judging from the industrial structure, changes to Taiwan's industrial structure are as shown in Figure 2. The percentage with regards to the output value of primary industry against the total local output value is small and less than 10\%. In addition, it continues its downward trend. Taiwan's industrial structure is currently in the process of transforming from a labor-capital intensive model to a high-tech intensive model. The proportionate 
output value of tertiary industry is gradually expanding, and since 1988, the percentage accounts for more than half of the economy and is currently close to $70 \%$. As a result, unlike many developed countries, the impact with regards to the percentage output value of primary industry to workers compensation is extremely weak. Since the percentage of primary industry accounts for very little, secondary and tertiary industries' percentages are totally linear; thus, they cannot be variables inserted into the model.

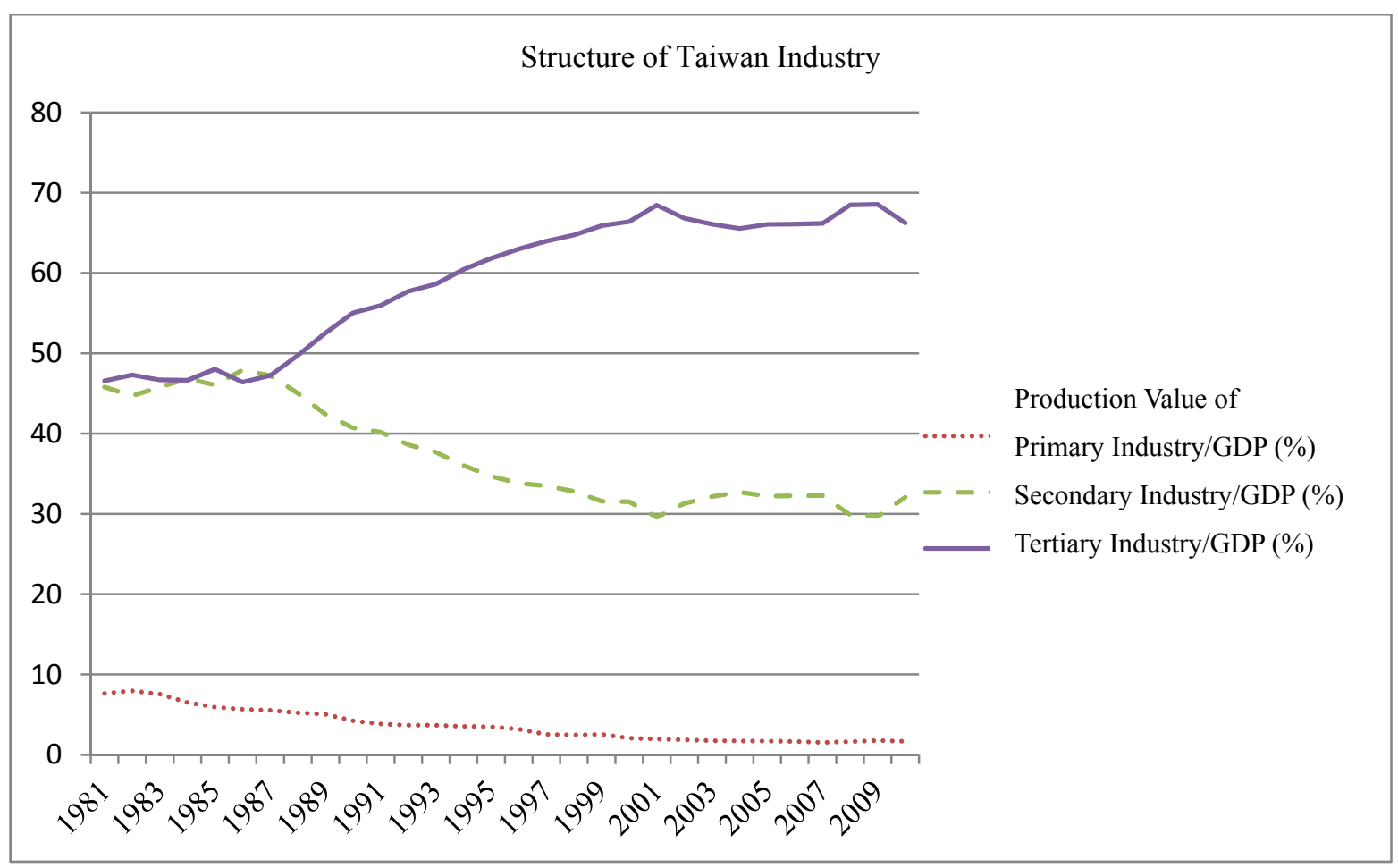

Figure 2. Structure of Taiwan industry

In the case of international trade, international competitiveness pertaining to export products is an important factor that influences the value of product export trade. Whether a product is competitive in the international market is based on the index of this product's international competitiveness (TCi). It is measured as a percentage between the difference between this product's export value (EXi) and import value (IMi) to the total export and import value (EX_i+IM_i). The calculation formula for this index is TCi $\in[-1,1]$.

$$
T C_{i}=\frac{E X_{i}-I M_{i}}{E X_{i}+I M_{i}}
$$

Amongst,

$$
\left\{\begin{array}{c}
-1 \leq T C_{i}<0 \text {, the competitiveness of Product } i \text { is relatively weak in international trade } \\
T C_{i}=0 \text {, the competitivensss of Product } i \text { is average in international trade; } \\
0<T C_{i} \leq 1 \text {, the competitiveness of Product } i \text { is relatively strong in international trade. }
\end{array}\right.
$$

Taiwan's top ten trading countries and regions are mainland China, the United States, Japan, Malaysia, Hong Kong, Singapore, South Korea, and Germany. Products traded are primarily mid-to-advanced level technology products. The research into the impact of Taiwan's competitiveness with regards to its export of mid-to-advanced level technology level products to other countries as against the share of worker compensation reflects the impact of Taiwan's competitiveness in import and export trade to the share of laborers, and also reflects the crowding effect of technical progress to the key labor factor. From a statistical point of view, the mean value, standard deviation, maximum and minimum values, and span in relation to Taiwan's competitiveness with regards to mid-to-advanced level technology products for its key trading countries are shown in Table 1 below. 
Table 1. Statistical analysis of the following countries international competitiveness in relation to the export of advanced technology products

\begin{tabular}{llllll}
\hline Indicators & Mainland China & U.S.A. & Japan & Malaysia & International \\
\hline Average & 0.055 & 0.273 & -0.349 & -0.140 & 0.584 \\
Standard Deviation & 0.590 & 0.083 & 0.316 & 0.114 & 0.043 \\
Maximum Value & 0.632 & 0.388 & 0.938 & 0.039 & 0.665 \\
Minimum Value & -0.998 & 0.148 & -0.602 & -0.296 & 0.537 \\
Span & 1.630 & 0.240 & 1.539 & 0.335 & 0.128 \\
\hline Indicators & Hong Kong & Singapore & South Korea & Germany & \\
\hline Average & 0.873 & 0.182 & -0.308 & 0.200 & 0.219 \\
Standard Deviation & 0.070 & 0.075 & 0.316 & 1.000 & \\
Maximum Value & 0.974 & 0.343 & 0.937 & -0.040 & \\
Minimum Value & 0.709 & 0.048 & -0.608 & 1.040 & \\
Span & 0.265 & 0.295 & 1.545 & & \\
\hline
\end{tabular}

As can be seen in Table 1, Taiwan's exports to mainland China experienced the greatest fluctuation since 1991, and in the competitiveness of mid-to-advanced level technology products, from the smallest value of -0.998 , this data point increased to 0.632 in 2007 . Taiwan's exports to the United States experienced the least fluctuation in the competitiveness of mid-to-advanced level technology products. However, the marker does decline from a high of 0.388 in 1998 to a low of 0.148 in 2008. Overall, fluctuation in Taiwan's export of mid-to-advanced level technology products on the international stage is very minimal - the smallest value being 0.537 and the largest value being 0.665. As a result, Model A utilizes Taiwan's competitiveness in the export of mid-to-advanced level technology products to mainland China since 1991 as the technical indicator of foreign trade to measure the impact of Taiwan's foreign trade as against the changes to the share of worker compensation. Model B utilizes Taiwan's competitiveness in the export of mid-to-advanced level technology products to the United States since 1991 as the technical indicator for foreign trade to measure the impact of Taiwan's foreign trade as against the changes to the share of worker compensation.

As shown in Figure 3 and with respect to all of Taiwan's products and services since 1967, the international competitive index of export products does not seem to exhibit any volatility. Taiwan's exports to the United States in the first 8 years experiences the least fluctuation in the competitiveness index of mid-to-advanced level technology products. While in 1998, it reaches the highest point. Thereafter, it starts to trend downwards. On the other hand, competitiveness of Taiwan's exports to mainland China with regards to mid-to-advanced level technology products experiences a steep increase. From 1991 to 2010, among the key export countries, competitiveness of Taiwan's export of mid-to-advanced level technology products to mainland China experience dramatic change, that is, competitiveness turns from the weakest to the strongest. As for competitiveness of Taiwan's exports to the United States with regards to mid-to-advanced level technology products, an inverted U curve is formed. 

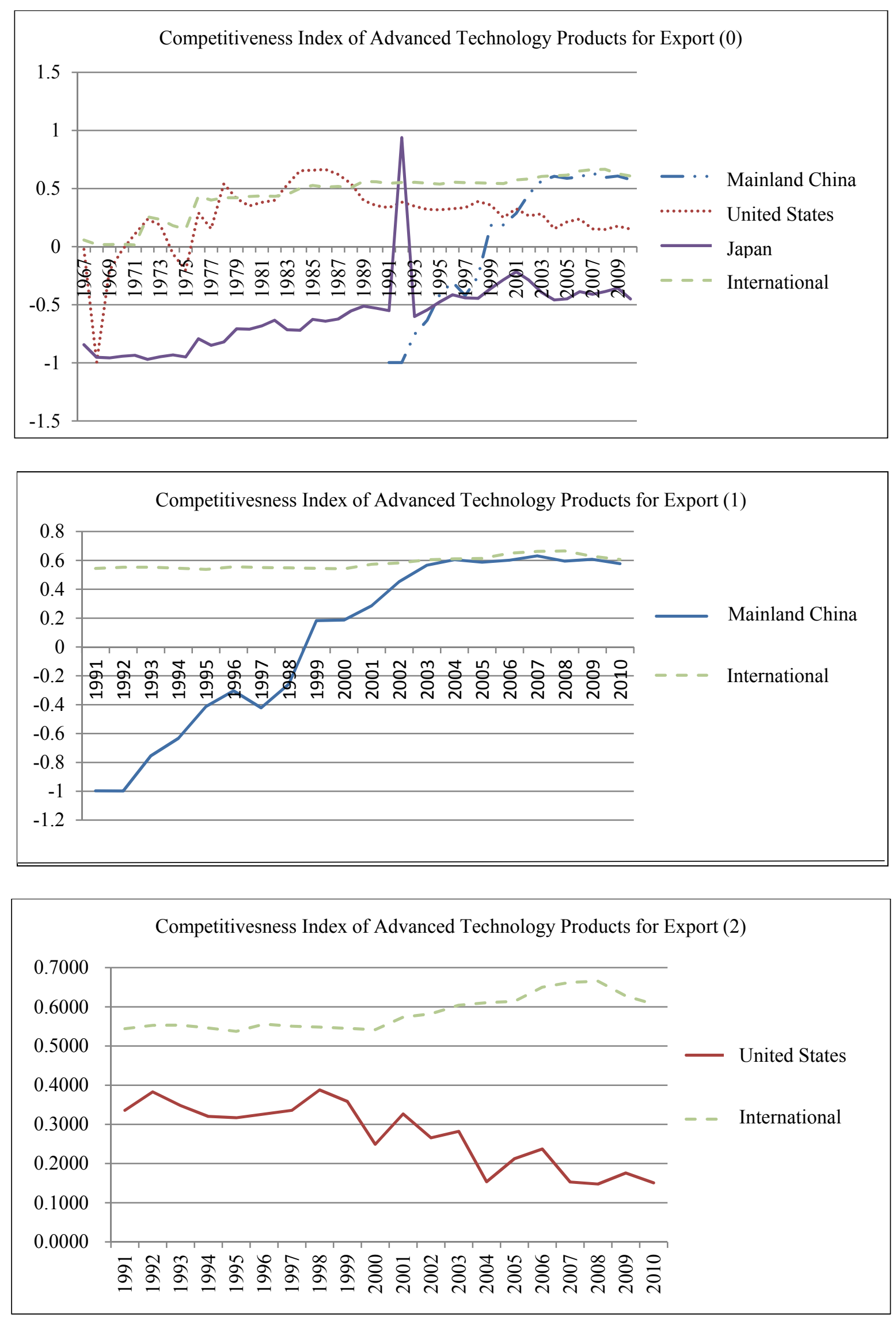

Figure 3. Competitiveness of export product 
From the point of view of individual labor quality, a worker's level of education will impact their personal level of income, be it high or low. By looking at Figure 4, Taiwan labor's level of education has experienced a steep rise. Internationally, the percentage of R\&D to GDP is used to measure a country or a region's technological competitiveness and core competitiveness. With regards to knowledge and technology (R\&D) investment, on a policy perspective, it can be used to influence the share of worker compensation. As can be seen in Figure 4, Taiwan's technology competitiveness is marking steady increases. As a result, in the process of economic and technology development, the important factor of technological competitiveness and labor's level of education can influence the share of worker compensation.

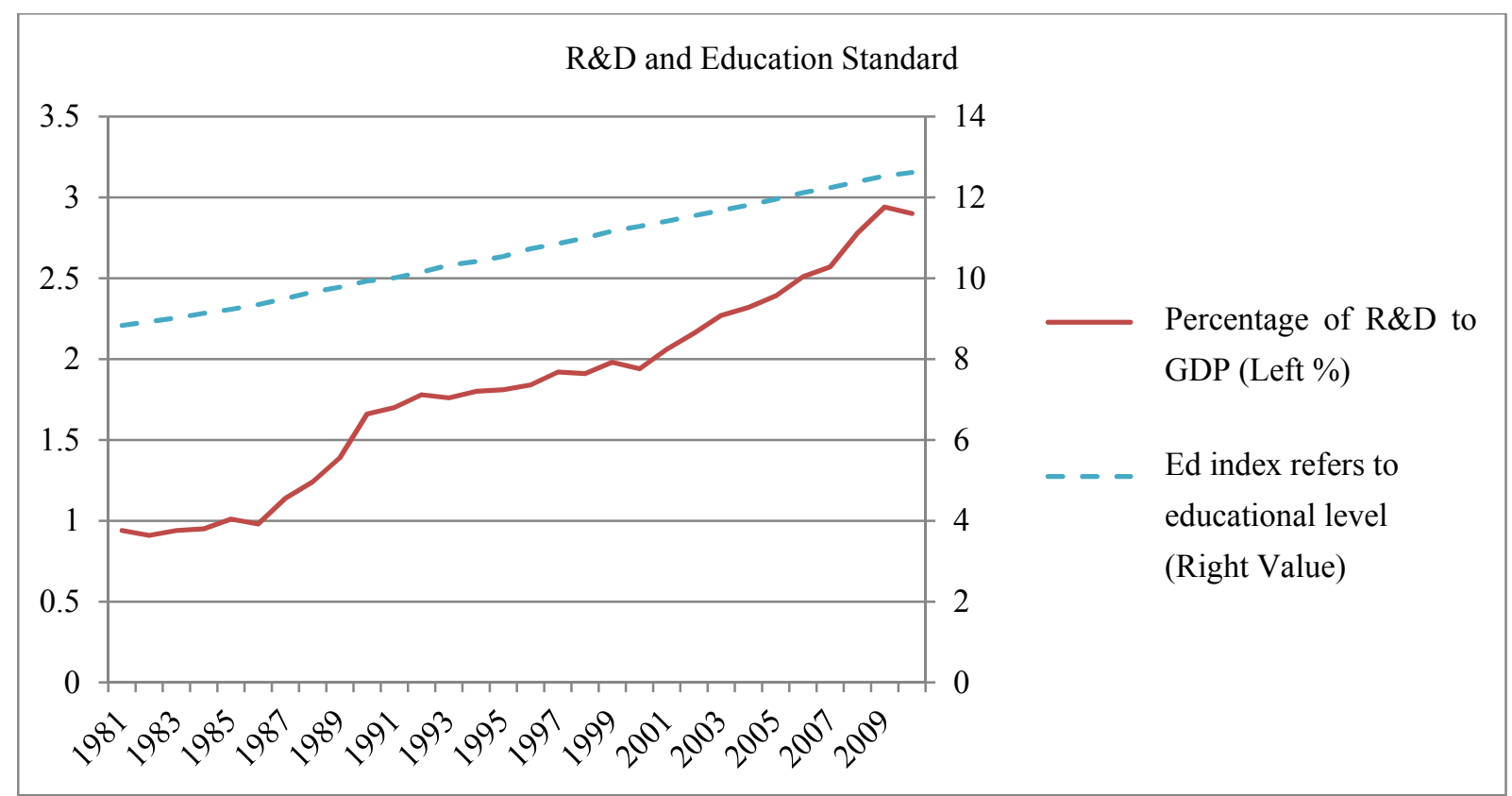

Figure 4. R\&D and education standard

Based on the above theories, analysis can be conducted in accordance with Taiwan's actual situation. That is, based on the setup of the influencing factors in relation to impact of workers compensation in production functions by Cobb-Douglas and the reference of Bai Chong En et al., and considering the use of economic globalization and the impact of transformation to industrial structure and technical progress, it is possible to utilize competitiveness with regards to mid-to-advanced level technology products (Taiwan's competitiveness of mid-to-advanced level products exported to mainland China as $\mathrm{MT}_{\mathrm{c}}$; Taiwan's competitiveness of mid-to-advanced level technology products exported to the United States as $\mathrm{MT}_{\mathrm{u}}$ ), foreign investment in Taiwan and share of total Taiwan internal investment to GDP (fky), percentage of R\&D to GDP (RD), share of total production value of secondary and tertiary industries to GDP (vsh), and labor's level of education (peo) as explanatory variables to construct an econometric model that is able to explain the factors that influence the share of worker compensation. In addition, based on the usage of heteroscedasticity to eliminate some logarithmic variables, it is possible to construct an econometric model that is able to explain the changes in worker share of compensation LS.

Model A:

$$
\ln (L S)=\alpha+\beta_{1} \cdot M T_{c}+\beta_{2} \ln (f k y)+\beta_{3} \ln (v s h)+\beta_{4} \ln (r d)+\beta_{5} \cdot p e o
$$

Model B:

$$
\ln (L S)=\alpha+\beta_{1} \cdot M T_{u}+\beta_{2} \ln (f k y)+\beta_{3} \ln (v s h)+\beta_{4} \ln (r d)+\beta_{5} \cdot p e o
$$

\section{Solutions to Model A}

Too many explanatory variables in Model A could easily lead to multicollinearity, which can affect the accuracy of the final estimates. According to AIC and SC guidelines, as well as DW examination and so forth, weak explanatory variables can be excluded. See Table 2. 
Table 2. Model solution

\begin{tabular}{|c|c|c|c|}
\hline Variables & Model $\mathrm{A}_{1}$ & Model $\mathrm{A}_{2}$ & Model $\mathrm{A}_{3}$ \\
\hline $\ln ($ fky) (Ratio of Capital Output) & & & $0.070004 *$ \\
\hline \multicolumn{4}{|l|}{ Ln(rd) (Knowledge R\&D) } \\
\hline \multicolumn{4}{|l|}{ Peo (Human Capital) } \\
\hline $\mathrm{R}^{2}$ & 0.926399 & 0.939014 & 0.949397 \\
\hline $\mathrm{SC}$ & -6.974780 & -7.013004 & -7.049845 \\
\hline
\end{tabular}

\subsection{Significance Test}

Each variable in Model A1 is tested for significance to $99 \%$; the $92.6 \%$ change in the share of worker compensation can be explained by an overall regression equation. Variables in Model A2 are tested for significance to $90 \%$; the $93.9 \%$ change in the share of worker compensation can be explained by an overall regression equation. In terms of the explanatory power of knowledge R\&D and direct investment from foreign companies in Model A3, they are tested for significance to $90 \%$; the $94.9 \%$ change in the share of worker compensation can also be explained. All three models have passed the F-test.

\subsection{Test of AIC and SC}

With regards to Model A1, Model A2, and Model A3, and according to the AIC and SC guidelines, as compared with Model 2, the proportion of secondary and tertiary industries total output value is added to Model A1-the value of AIC and SC decreases and the value of R2 increases. As compared with Model A3, investment rate is added to Model A2, and the value of AIC and SC decreases and R2 increases. Based on the AIC and SC guidelines, Model A3 is ultimately selected so that it is easier to explain the changes in the share of worker compensation.

\subsection{Correlation Test}

With regards to Model A3, correlation and auto-correlation of each variable do not exist. Residual sequence is a stable sequence and both pulse response and variance decomposition can be further discussed.

Lastly, according to Model 2, the deciding factors of the share of worker compensation in Taiwan can be confirmed in the econometric model as follow:

$$
\ln (l s)=-0.287463-0.019887 M T c+0.07 \ln (f k y)-2.758 \ln (v \operatorname{sh})
$$

Judging from the finalized model, the stronger the competitiveness with regards to the export of mid-to-advanced level technology products to mainland China, the less the percentage of workers compensation to GDP. This is consistent with the theory of the $\mathrm{H}-\mathrm{O}$ model, which stipulates that the final resource allocation from trade between developed regions and developing regions, and the flow of capital and technology from developed regions to less developed regions are similar.

Relative to mainland China, Taiwan's level of economic development is higher; when trading with mainland China, the percentage of mid-to-advanced level technology products is the highest. As a result of using the mid-level technology product competitiveness index to measure trade with mainland China, the super competitive capital and technology attributes crowd out key labor factors within the share of GNI. Since Taiwan's foreign trade has in earlier years shifted from a labor-intensive model to a high-end capital technology-intensive model, the greatest advantage is enjoyed by mid-to-advanced level technology products that bring gains from key capital technical factors that crowd out the gains of Taiwan labor and thus result in gradual decline in the share of worker compensation. 
Increases in investments are able to pull and drive higher shares of worker compensation. That is, by increasing one unit of investment, it is possible to increase worker compensation by $7 \%$. When analyzing foreign investment and Taiwan's local investment separately, findings from the research indicate that the explanatory power is still insufficient. However, if both are analyzed together, the explanatory power is significant.

The fluctuation with regards to the percentage of total output between secondary and tertiary industries and the share of worker compensation is negatively correlated. Combining the coefficient in front of the total percentage share between secondary and tertiary industries stipulates that the rapid development of the tertiary industry due to technology innovation results in disutility to the share of worker compensation.

\section{Test of Model A}

\subsection{Stability Test}

The stability test was conducted on $\ln (\mathrm{ls}), \mathrm{MT}_{\mathrm{c}}, \ln (\mathrm{vsh})$, and $\ln (\mathrm{fky})$, garner $\ln (\mathrm{ls}), \ln (\mathrm{fky})$ is $\mathrm{I}(1)$ sequence. $\ln (\mathrm{vsh})$ and $\mathrm{MT}_{\mathrm{c}}$ is $\mathrm{I}(2)$ sequence.

\subsection{Variance Decomposition}

According to the AIC and SC guidelines, selection of the two pairs of model as the post optimal lag to conduct variance decomposition indicates from Figure 5 that the model structure is stable.

\section{Inverse Roots of AR Characteristic Polynomial}

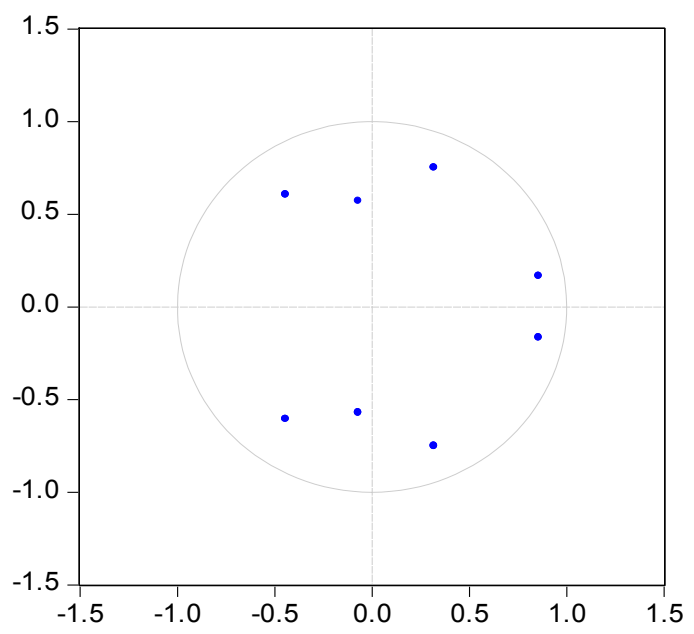

Figure 5. VAR test figure

$\ln (\mathrm{ls}), \ln (\mathrm{fky}) \quad 1 \mathrm{st}$ level difference, $\ln (\mathrm{vsh})$ and $\mathrm{MT}_{\mathrm{c}} 2$ nd level difference. For results of variance decomposition, see Table 3 and Figure 6.

Table 3 Variance decomposition table

\begin{tabular}{llllll}
\hline Period & S.E. & DFKY & DLS & DVSH & DMTC \\
\hline 1 & 0.038922 & 7.235279 & 92.76472 & 0.000000 & 0.000000 \\
2 & 0.043536 & 21.71663 & 68.92554 & 0.327840 & 9.029989 \\
3 & 0.049505 & 38.21983 & 45.13080 & 1.957164 & 14.69220 \\
4 & 0.051633 & 34.84885 & 35.62875 & 3.967766 & 25.55463 \\
5 & 0.052962 & 35.08925 & 36.05342 & 3.805719 & 25.05161 \\
6 & 0.054840 & 36.47109 & 35.87147 & 3.640374 & 24.01707 \\
7 & 0.055176 & 34.89675 & 35.31953 & 5.473008 & 24.31071 \\
8 & 0.056372 & 34.15419 & 35.40228 & 6.447614 & 23.99592 \\
9 & 0.056521 & 34.63695 & 34.73208 & 6.452142 & 24.17883 \\
10 & 0.056879 & 34.39895 & 34.47108 & 6.397810 & 24.73216 \\
\hline
\end{tabular}


Variance Decomposition

Percent DLS variance due to DFKY

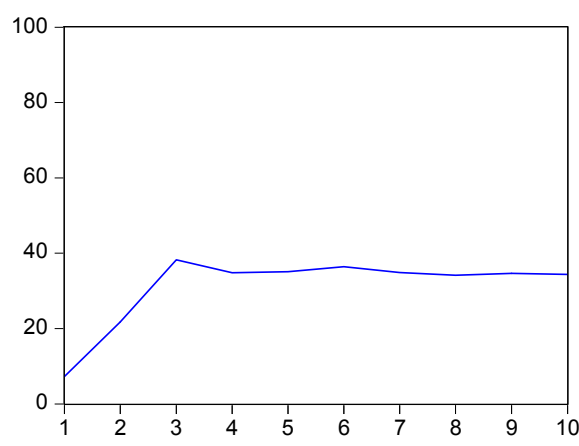

Percent DLS variance due to DVSH

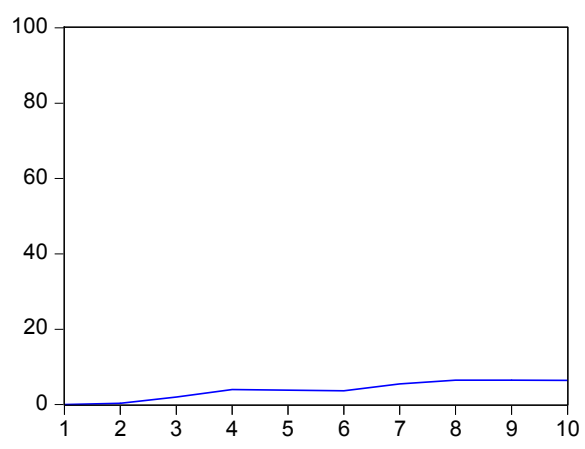

Percent DLS variance due to DLS

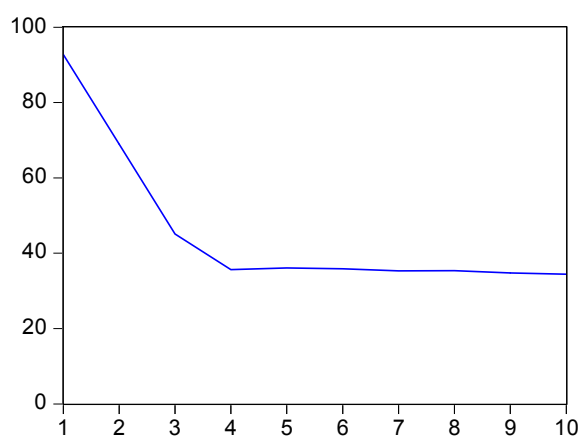

Percent DLS variance due to DMTC

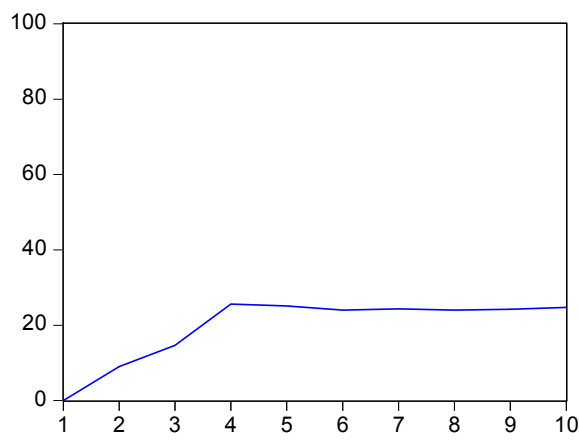

Figure 6. Variance decomposition figure

Looking at both Table 3 and Figure 6, the share of worker compensation in Taiwan is primarily influenced by individual factors and in the long run is likely to gradually weaken. Affected by investment fluctuation and competitiveness in the export of mid-to-advanced level technology products, the situation will be stable after four years. Affected by investment, the share of worker compensation in Taiwan is estimated to be around $34.6 \%$. As for the influence of competitiveness with regards to the export of mid-to-advanced level technology products, it is estimated to be around $24 \%$. In the long term, the factors affecting the industrial structure are likely to increase.

\subsection{Pulse Response}

Changes to each explanatory variable by one standard deviation could lead to fluctuation in worker share, as shown in the function diagram of pulse response in Figure 7. 
Response to Cholesky One S.D. Innovations \pm 2 S.E.

Response of DLS to DMTC

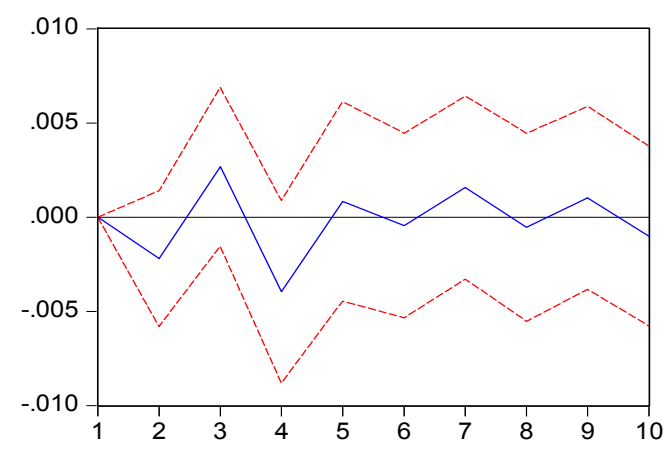

Response of DLS to DFKY

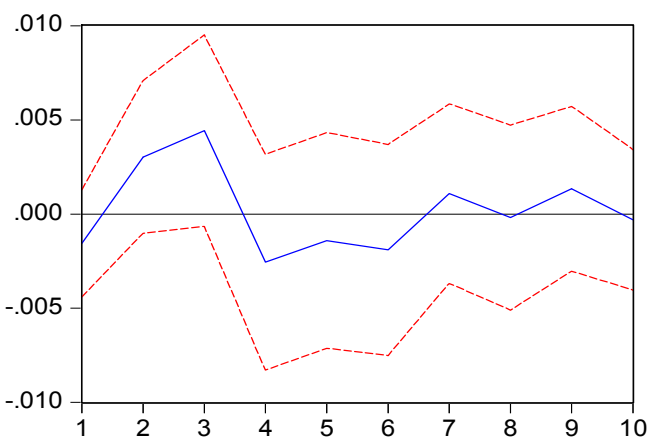

Response of DLS to DVSH

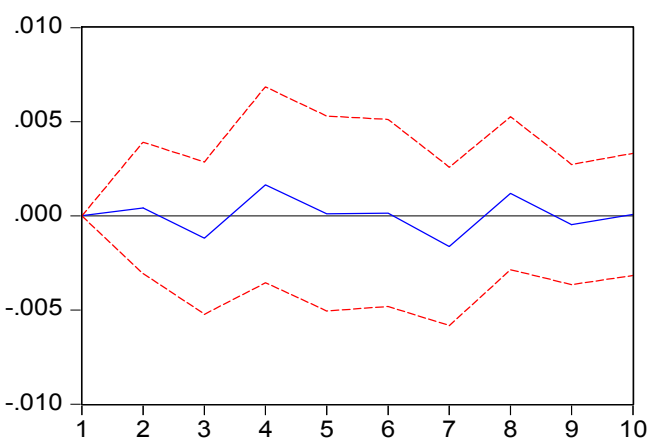

Figure 7. Function diagram of pulse response

As can be seen from Figure 7, changes in one unit of standard deviation to each explanatory variable will lead to a wider and increased fluctuation to worker compensation in Taiwan. This relative and bigger fluctuation is due to investment, transformation of industrial structure, and competitiveness with regards to the trading of mid-to-advanced level technology products from 1991 to 2010.

\section{Solutions to Model B}

Too many explanatory variables in Model B could easily lead to multicollinearity, which can affect the accuracy of the final estimates. According to the AIC and SC guidelines, as well as DW examinations and so forth, explanatory variables that are relatively weak can be excluded. See Table 4. 
Table 4. Solutions to model B

\begin{tabular}{|c|c|c|c|}
\hline Variable & Model B 1 & Model $\mathrm{B}_{2}$ & Model B 3 \\
\hline $\mathrm{C}$ & $-0.366322 * * *$ & $-0.374422 * * *$ & $-0.321377 * * *$ \\
\hline Mtu (Competitiveness of Advanced Technology Products Exported to U.S.A.) & $0.234668 * * *$ & $0.061695 * *$ & $0.057352 * *$ \\
\hline $\ln (\mathrm{fky})$ (Ratio of Capital Output) & & & $0.077686^{*}$ \\
\hline Ln(vsh) (Total Proportion of 2nd and 3rd Industry) & & $-5.198961 * * *$ & $-4.810899 * * *$ \\
\hline \multicolumn{4}{|l|}{ Ln(rd) (Knowledge R\&D) } \\
\hline \multicolumn{4}{|l|}{ peo (Human Capital) } \\
\hline $\mathrm{R}^{2}$ & 0.650837 & 0.937303 & 0.950400 \\
\hline F-statistic & 33.55188 & 127.0737 & 102.1932 \\
\hline Durbin-Watson & 0.827621 & 1.780756 & 1.992829 \\
\hline AIC & -5.517469 & -7.134701 & -7.269013 \\
\hline $\mathrm{SC}$ & -5.417895 & -6.985341 & -7.069867 \\
\hline
\end{tabular}

\subsection{Significance Test}

The explanatory effect in each variable in Model B1 is tested for significance to $99 \%$ confidence level, although the explanatory power with regards to the total regression equation is only $65.08 \%$ and DW value is extremely small. Each variable in Model B2 is tested to a significance of $95 \%$ confidence level. Thus, in totality, the change in the share of worker compensation is explainable at $93.7 \%$. Both $\mathrm{R}^{2}$ and $\mathrm{DW}$ also increase. According to the AIC and SC guidelines, adding an industrial structure factor equation can strengthen the explanatory power. Model B3 adds capital output ratio as a new explanatory variable, and according to the AIC and SC guidelines, capital output ratio can be used as an explanatory variable and has had significance tested to $10 \%$ confidence level. It is thus capable of explaining $95 \%$ of the changes in the share of worker compensation.

With regards to Model B3, among each variable, there is no correlation and auto-correlation. The residue sequence is a stationary sequence. As for both impulse response and variance decomposition, they can be further discussed.

Lastly, in Model B, it can be confirmed that the deciding factors of the share of worker compensation in Taiwan with regards to the econometric model are as follows:

$$
\ln (l s)=-0.321377+0.057352 M T u+0.077686 \ln (f k y)-4.810899 \ln (v s h)
$$

Judging from the finalized model, the stronger the competitiveness with regards to the export of mid-to-advanced level technology products to United States, the greater the percentage of worker compensation to GDP. This is consistent with the theory of the $\mathrm{H}-\mathrm{O}$ model, wherein it stipulates that the final resource allocation from trade between developed regions and developing regions, and the flow of capital and technology from developed regions to less developed regions are similar. Relative to the United States, Taiwan's level of economic development is lower and when trading with the United States, the competitiveness with regards to mid-to-advanced level technology products against the crowding out effect to workers is not obvious. Instead, the increase in the share of worker compensation is driven by the strengthening of the export competitiveness of mid-to-advanced level technology products.

Increases in investment are able to pull and drive the ratio of worker remuneration upwards. One unit of investment added to Model B3 is able to increase the share of worker compensation by $7.76 \%$, and this is comparative to Model A3. When analyzing foreign investment and Taiwan's local investment separately, findings from the research indicate that the explanatory power is still insufficient. However, if both are analyzed together, the explanatory power is strengthened and can guarantee a $90 \%$ level of significance.

The fluctuation with regards to the proportion of total output between secondary and tertiary industries and the share of worker compensation is negatively correlated. As compared with Model A3, the disutility of the total output of the secondary and tertiary industries is enhanced when it accounts for the share of GDP. This indicates that the competitiveness with regards to the export of mid-to-advanced level technology products to mainland China divides and deprives Taiwan of further improvement in its personal industrial structure, especially in the areas of technical progress, thereby causing a crowding effect on the share of worker compensation.

\section{Tests of Model B}

\subsection{Stability Test}

Stability testing was conducted on $\ln (\mathrm{ls}), \mathrm{MT}_{\mathrm{u}}, \ln (\mathrm{vsh})$, and $\ln (\mathrm{fky})$, garner $\ln (\mathrm{ls}), \ln (\mathrm{fky})$, and $\mathrm{MT}_{\mathrm{u}}$ is 
$\mathrm{I}(1)$ sequence. $\ln (\mathrm{vsh})$ is $\mathrm{I}(2)$ sequence.

6.2 Variance Decomposition

According to the AIC and SC guidelines, two pairs of models from the post optimal lag are selected to conduct the variance decomposition test. Figure 8 below indicates that the model structure is stable.

\section{Inverse Roots of AR Characteristic Polynomial}

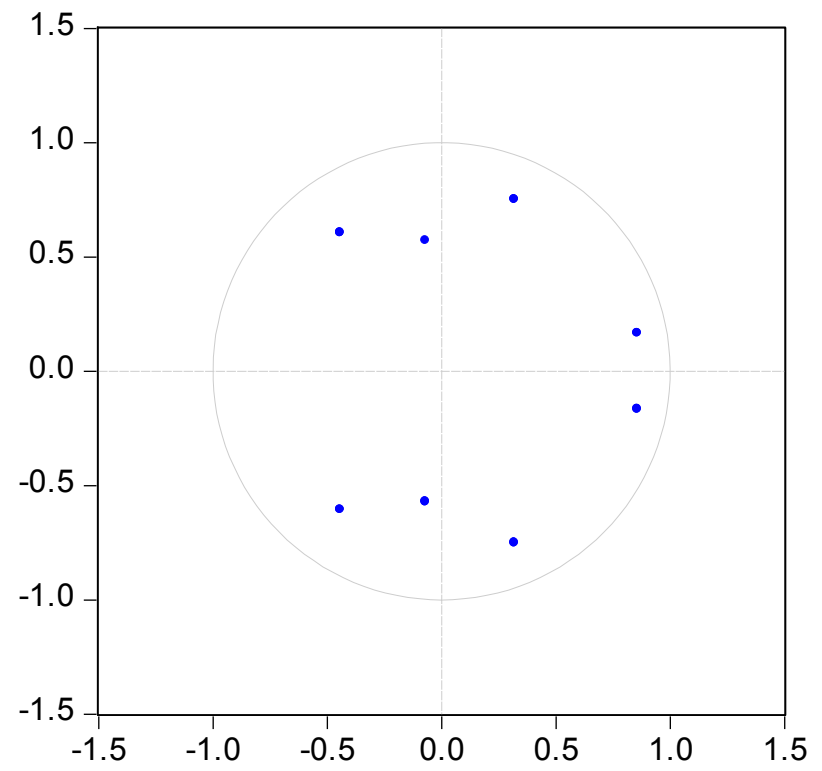

Figure 8. VAR test figure

$\ln (\mathrm{ls}), \ln (\mathrm{fky})$, and $\mathrm{MT}_{\mathrm{u}}$ 1st level difference, $\ln (\mathrm{vsh})$ 2nd level difference. For results of variance decomposition, see Table 5 and Figure 9.

Table 5. Variance decomposition

\begin{tabular}{llllll}
\hline Period & S.E. & DMTU & DFKY & DLS & DVSH \\
\hline 1 & 0.058063 & 0.242159 & 0.463371 & 99.29447 & 0.000000 \\
2 & 0.070961 & 35.77696 & 9.841248 & 54.35623 & 0.025567 \\
3 & 0.073924 & 37.43216 & 15.72704 & 39.04497 & 7.795838 \\
4 & 0.077260 & 33.08546 & 13.62846 & 45.97596 & 7.310125 \\
5 & 0.078997 & 32.21987 & 14.98778 & 45.41950 & 7.372849 \\
6 & 0.082874 & 30.10272 & 20.62331 & 42.38038 & 6.893583 \\
7 & 0.086676 & 30.59085 & 20.16755 & 41.47103 & 7.770575 \\
8 & 0.087211 & 30.70401 & 19.87093 & 40.12690 & 9.298153 \\
9 & 0.087605 & 30.73296 & 19.95644 & 39.89755 & 9.413053 \\
10 & 0.088555 & 30.54118 & 19.98533 & 39.86326 & 9.610241 \\
\hline
\end{tabular}




\section{Variance Decomposition}

Percent DLS variance due to DMTU

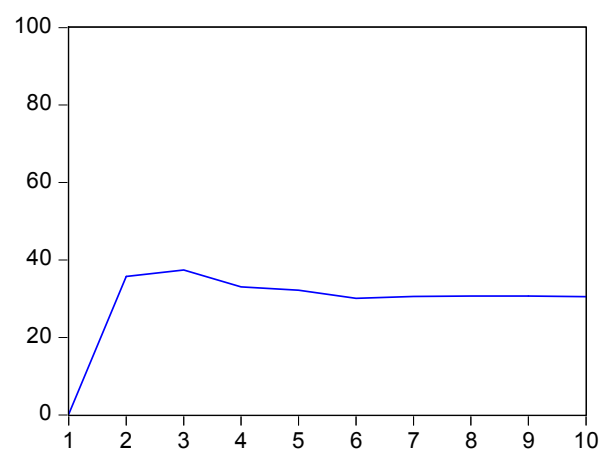

Percent DLS variance due to DLS

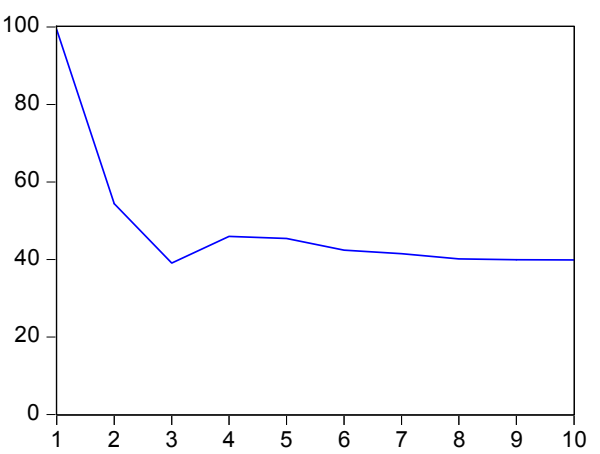

Percent DLS variance due to DFKY

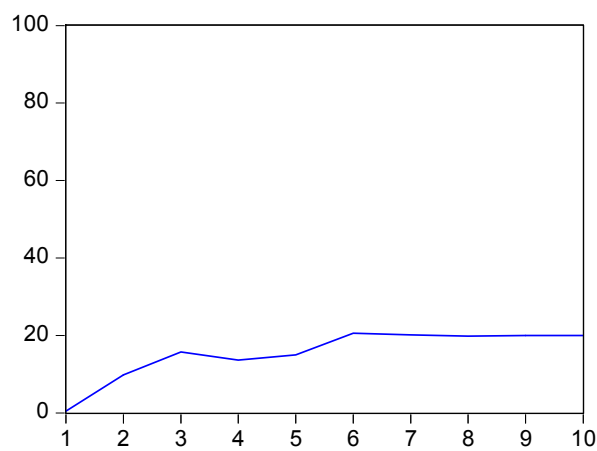

Percent DLS variance due to DVSH

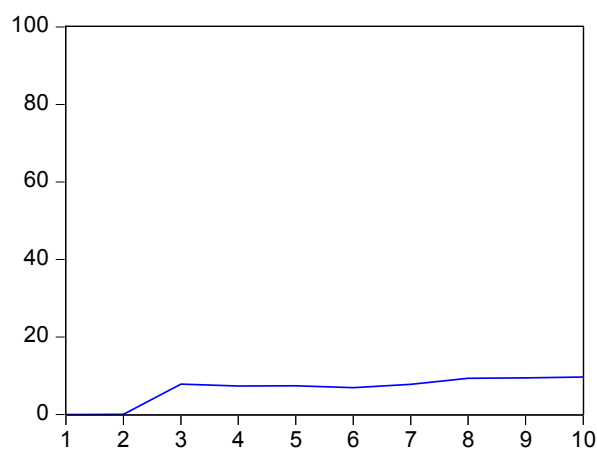

Figure 9. Variance decomposition figure

Looking at both Table 5 and Figure 9, the share of worker compensation in Taiwan is primarily influenced by individual factors, and this is sharply weakened at the beginning of the second stage. Affected by the competitiveness with regards to the export of mid-to-advanced level technology products to the United States, the share of worker compensation in Taiwan reaches the highest point of 37.4 at the third stage. In the long run, the fluctuation is relatively minimal and estimated at approximately $30.5 \%$. If influenced by investment, the long-term outlook is around $20 \%$, and as such, the impact to the share of worker compensation as against industrial structure increases in the long run.

\subsection{Pulse Response}

Changes to each explanatory variable by one standard deviation could lead to fluctuation in worker share, as shown in the function diagram of pulse response in Figure 10. 
Response to Cholesky One S.D. Innovations \pm 2 S.E.

Response of DLS to DMTU

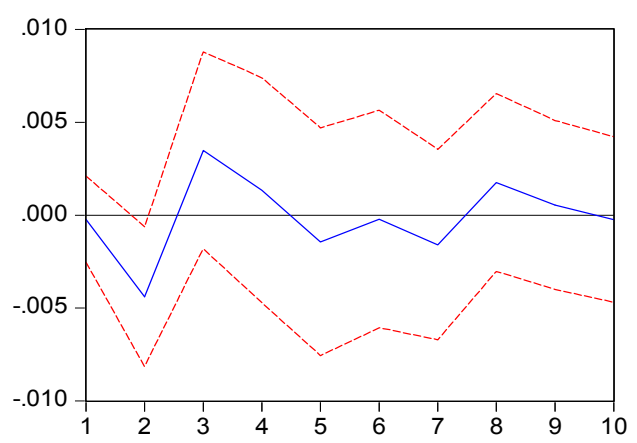

Response of DLS to DFKY

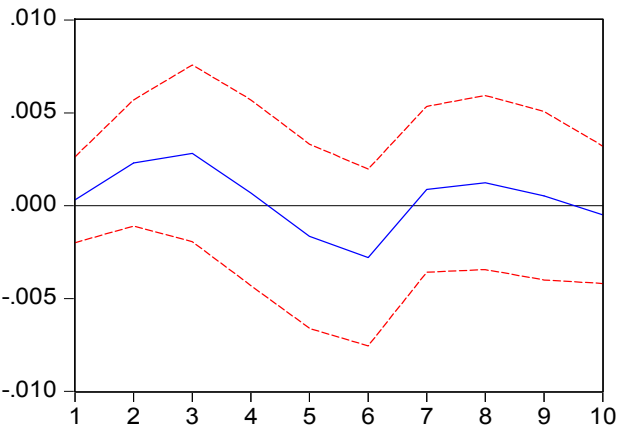

Response of DLS to DVSH

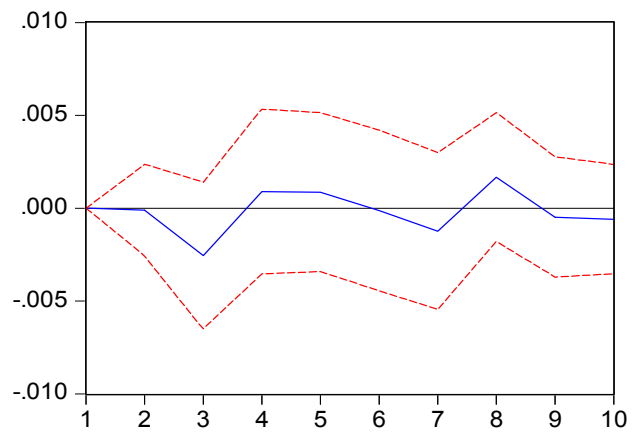

Figure 10. Functional diagram of pulse response

As can be seen from Figure 10, changes in one unit of standard deviation to each explanatory variable can lead to a wide and increased fluctuation to worker compensation in Taiwan. Looking at the earlier days when Taiwan exported to the United States, the fluctuation between the share of worker compensation to the competitiveness of mid-to-advance technology products and industrial structure was negatively impacted. However, in the long run, positive and negative fluctuations will overlap and cross.

\section{References}

Bentolila, S., \& Saint-Paul, G. (2003). Explaining Movements in the Labor Share. Contributions to Macroeconomics, 3(1), 1103-1137. http://dx.doi.org/10.2202/1534-6005.1103

Changyuan, L., \& Jun, Z. (2009). Labor Income Share and Economic Development: An Empirical Study Based on Chinese Industry-level Data. Social Sciences in China, 4, 5. http://dx.doi.org/10.1080/02529200903342750

De Serres, A., Scarpetta, S., \& De La Maisonneuve, C. (2001). Falling wage shares in Europe and the United 
States: How important is aggregation bias? Empirica, 28(4), 375-401. http://dx.doi.org/10.1023/A:1013922621303

Decreuse, B., \& Maarek, P. (2008). FDI and the labor share in developing countries: A theory and some evidence.

En, B., \& Jie, Q. (2010). Deciding Factors of Share of Labor Income: Evidence from China's Panel Data. World Economy, 12, 3-27.

Findlay, R. (1960). Economic Growth and the Distributive Shares. The Review of Economic Studies, 167-178. http://dx.doi.org/10.2307/2296078

Guscina, A. (2006). Effects of Globalization on Labor's Share in National Income. International Monetary Fund.

Harrison, A. E. (2002). Has Globalization Eroded Labor's Share? Some Cross-Country Evidence. Mimeo, 46.

Hu, C., \& Li, L. (2009). Research of China's Labor Market. In Relation to Marx's Based Approach. Modern Economic Research, 10, 51-54.

Morel, L. (2005). A sectoral analysis of labour's share of income in Canada. Research Department, Bank of Canada.

Xue, B. (2007). Analysis of Taiwan Trade Structure and Relative Strengths. Journal of Hubei University of Economics, 5(4), 64-70.

Yuan, L. (2008). Kaldor's Rethinking of "Stylized Facts": Proportional Analysis of Labor Income. World Economy, 11 .

\section{Copyrights}

Copyright for this article is retained by the author(s), with first publication rights granted to the journal.

This is an open-access article distributed under the terms and conditions of the Creative Commons Attribution license (http://creativecommons.org/licenses/by/3.0/). 